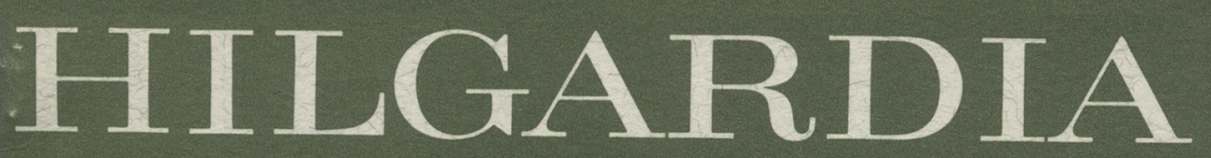

DOURNAL OF AGRICULTURAL SCIENCE PUBLISHED BY THE CALIFORNIA AGRICULTURALEXPERIMENT STATION

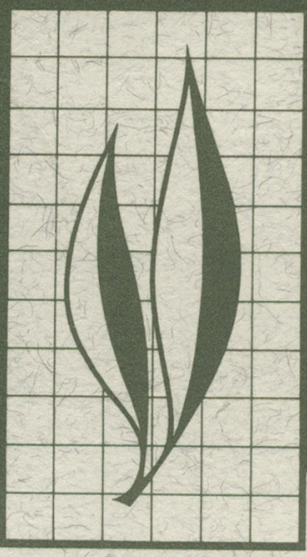

Volume 44, Number 3 - December, 1976

\title{
Ultrastructure of the Epidermis of Developing, Ripening, and Senescing Navel Oranges
}

William W. Thomson and Kathryn Platt-Aloia 


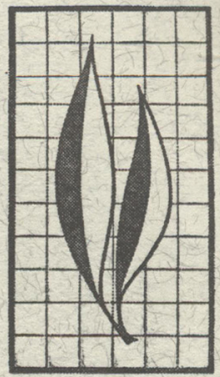

\begin{abstract}
Electron microscope studies revealed that throughout the development, maturation, and after-ripening of Navel orange fruits, the epidermal cells contained typical organelles. There were few significant changes in the ultrastructure of the organelles during these stages. However, there was considerable variation in the vacuoles, as well as changes in cytoplasmic inpockets and membranous configurations associated with the tonoplast, and changes in vacuolar content. These changes and variations probably indicate that the vacuoles have an important role as lysosomal compartments in accumulating and recycling cellular material during these stages. With early and late senescence there was a decrease in cytoplasmic organelles and a partial loss of membrane definition, indicating that metabolic dysfunctions associated with senescence may be related to the loss of compartmentation and the organizational integrity of the cells. Also with senescence, the vacuoles became filled with granular and lipid material, an indication that a reduction in the lytic and recycling capacity may have occurred. Dissolution of wall material also took place during this period. The final stage of degeneration was characterized by a loss of definition of membranes and organelles.
\end{abstract}




\section{Ultrastructure of the Epidermis of Developing, Ripening, and Senescing Navel Oranges}

\section{INTRODUCTION}

Over THE PAST DECADE, numerous studies have been made on various ultrastructural aspects of plant senescence, including ripening fruits (see Butler and Simon, 1971, for review). Ripening is generally considered irreversible, with the entire process being determinate and eventually leading to the death of the cells and tissues (Biale, 1964; Sacher, 1973). Earlier studies on plastid changes associated with ripening and regreening in Valencia oranges indicated that the process may be divided into two general phases: 1) changes associated with the development and ripening of the fruit, and 2) changes occurring after ripening and the subsequent death of the cells and tissue (Thomson, 1966; Thomson, Lewis, and Coggins, 1967).

In the present study, our goal was to investigate the sequential changes in ultrastructure which occur during the development, ripening, and senescence of Navel oranges. We limited our study to the epidermis to avoid the difficulties which could arise with material that was more heterogeneous, both structurally and functionally. We tried to find whether common cytological changes underlie developmental, and particularly senescent, changes in plant tissues (Butler and Simon, 1971).

\section{MATERIALS AND TECHNIQUES}

Navel orange (Citrus sinensis) fruits were collected from the same two trees in the University of California, Riverside, groves at 1 - to 2 -week intervals during the 1971-1972 season. The more frequent samplings (at 1-week intervals) were made during color change (November) and at the onset, and during the progression of, senescence (March and May). The fruits ranged from small and dark green, harvested in June, and ripe and dark orange, harvested in November and December, to the slightly shrunken, soft, dark orange fruits that had been left on the tree through the summer of the year following ripening. Samples of the fruits were prepared for electron microscopy as outlined below, and then examined. Samples of the different stages were also taken in subsequent years and examined electron microscopically.

A piece of the outer portion of the rind ( 1-2 $\mathrm{mm}$ thick) was removed with a razor blade, placed in fixative, and cut into pieces $\sim 1-2 \mathrm{~mm}^{2}$. The tissue was fixed at room temperature for 1 to $2 \frac{1}{2} \mathrm{hr}$ in either Karnovsky's glu-

\footnotetext{
* University of California, Riverside.
} 
taraldehyde-paraformaldehyde fixative (Karnovsky, 1965) or in 1.25-2.5\% phosphate-buffered glutaraldehyde, $\mathrm{pH}$ 7.0. In one instance, $1 \%$ ammonium carbonate was added during the last $10 \mathrm{~min}$ of fixation. All samples were washed 5-20 min in phosphate buffer, then for 1 to $1 \frac{1}{2} \mathrm{hr}$ in $1 \%$ phosphatebuffered osmium tetroxide. The tissue was dehydrated in an acetone series and embedded in epoxy resin (Spurr, 1969). Thin sections made using a Porter-Blum MT-2 ultramicrotome were placed on uncoated copper grids and stained with $1 \%$ aqueous uranyl acetate for 1-2 hr. This was followed by an application of Reynolds' lead citrate (Reynolds, 1963) for 1-2 min.

\section{OBSERVATIONS}

The development, ripening, and senescence of a fruit constitute a continuous process, and definitive demarcations between stages in the process are difficult to determine. We divided the sequence into a series of stages delineated by those common ultrastructural features of the epidermal cells which could be correlated with age and appearance of the fruit. As discussed later, even though in any one sample, variations in ultrastructure existed, there was a particular family of ultrastructural features which was characteristic of the epidermal cells of each stage; these ultrastructural patterns differed for each stage.

\section{Early Dark Green (July and August)}

In the epidermal cells of the dark green fruits there were small to large vacuoles (Figs. 1-3, v). In many instances the vacuoles were closely associated with each other (Fig. 1). Small vacuolar pockets, apparently protruding into the large vacuoles from the cytoplasm, were observed frequently (Fig. 1, arrows). The vacuoles generally contained a fine, granular material. A common observation was the presence, in the same cell, of vacuoles filled with densely packed granules, and of other vacuoles with a less dense granular content (Fig. 3). Also, membranebound regions in the vacuoles completely lacking granules were fre- quently evident (Fig. 1, o). Occasionally small vesicles were present within the vacuoles (Fig. 1, sv), and small lipid bodies were associated with both the inner and outer surface of the vacuolar membrane (Figs. 1, 2, lv).

The nuclei tended to be positioned near the internal periclinal wall (Fig. $1, n)$. They were characterized by a condensed nucleolus, and by chromatin which was generally associated with the inner membrane of the nuclear envelope. Commonly, there was an enlargement of the perinuclear space between the two membranes of the envelope (Figs. 1, 2 ps).

In the cytoplasm there were numerous ribosomes, which primarily occurred in aggregates (Fig. 2, r). The mitochondria (Figs. 1, 2, m) appeared normal, and the plastids were few in number and tended to be elongate in form. One or two small grana were present in the plastids, and there were large plastoglobuli. Also present were lamellae, which tended to be semicircular in conformation (Fig. 2, p). Golgi bodies, often associated with numerous small vesicles, were observed in these cells (Fig. 2, g). The groundplasm of the cells was reasonably dense, and lipid bodies were relatively common. These varied in size from small to rather large, and often were associated with organelles, particularly mitochondria and plastids (Fig. 2, 1). The plas- 


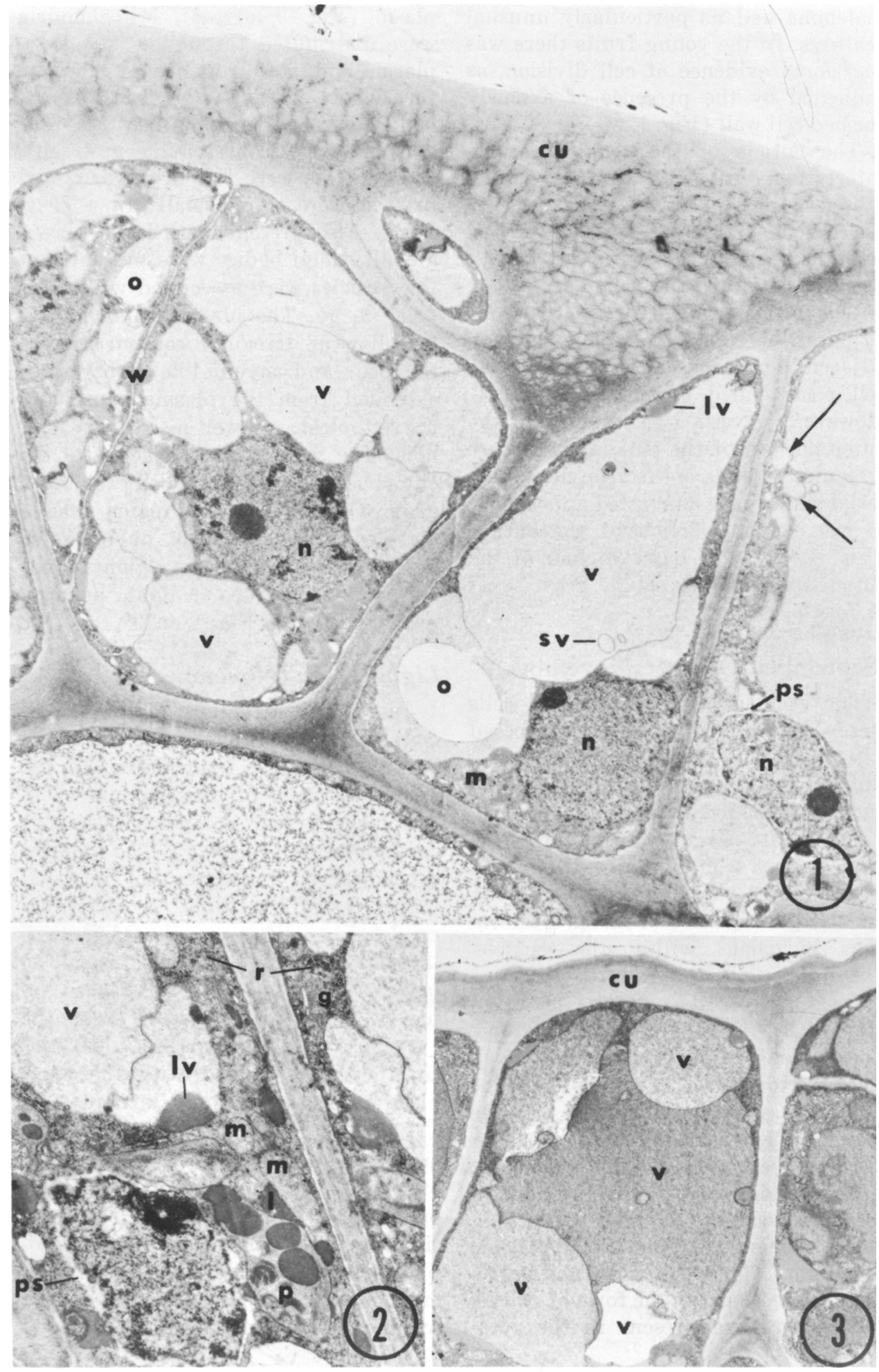

Figs. 1-3. Epidermal cells of young, dark green fruits. Note the variations in the number and content of the vacuoles (v). 1) $\times 7,400 ; 2) \times 14,600 ; 3) \times 7,700$. 
malemma had no particularly unusual features. In the young fruits there was occasional evidence of cell division, as indicated by the presence of a newly formed cell wall (Fig. 1, w).

The cuticle of the cells had some interesting features. In the young oranges, the wall area adjacent to the outer surface of the cell tended to stain a light gray, with the density increasing toward the periphery of the cuticle (Fig. 3, cu). In slightly older oranges, the wall and cuticular region adjacent to the outer perimeter of the cell also tended to stain light gray. However, between this region and the outer portion of the cuticle there were irregular strands of electron-dense material which gave a marbled appearance to the central portion of the cuticle (Fig. 1, cu). The outer surface of the cuticle stained an even light gray.

\section{Late Dark Green}

\section{(September, October, November)}

The vacuoles in the epidermal cells were large and partially chambered with peripheral pockets (Fig. 4, v). Further, protoplasmic strands frequently extended through the vacuole. The general background content of the vacuoles was a fine, evenly distributed granular material. Of particular interest was the presence of many membranous inclusions within the vacuole. These inclusions generally consisted of one or more nested groups of membranes (Fig. 4, my). Also, myelin-like membranous configurations extended from the tonoplast, as well as from the cytoplasm and plasmalemma, into the vacuole (Fig. 4, arrow).

The nuclei appeared similar to those in the early green fruits, and tended to be positioned near the wall of the cell. Small elements of rough endoplasmic reticulum (Fig. 4, er), and many aggregates of ribosomes in the form of spirals and loops, were present in the cyto- plasm (Fig. 5, arrow). Mitochondria were distributed throughout the cytoplasm, and both round and elongate forms were evident (Fig. 4, m). Microbodies with a homogeneous granular matrix were also present (Fig. $4, \mathrm{mb}$ ). The plastids were few in number, and in each were a few small grana (Fig. $4, \mathrm{p})$. Also present were large plastoglobuli. Golgi bodies were present, but few vesicles were associated with them (Fig. 4, g). The plasmalemma tended to follow an irregular contour around the cell, and myelin-like elaborations extended from the plasmalemma into the cytoplasm, as well as into the vacuole. The wall region adjacent to the outer boundary of the cell was light gray. Outside of this region was a marbled zone consisting of irregular dense lines. The outer region of the cuticle appeared as a light, homogeneous gray zone (Fig. 4, cu).

\section{Light Green (November)}

Just prior to the appearance of the definite yellow-orange color, the fruits became relatively light green. In the epidermal cells of these fruits there were usually four to six large vacuolar compartments (Fig. 6, v). The vacuoles contained a fine granular material which varied from light to moderately condensed in different cells. Of particular note was the presence of small to large vacuolar pockets, or vesicles, apparently protruding inward from the cytoplasm (Fig. 6, arrows). Myelinlike bodies associated with the tonoplast were observed only infrequently.

In the cytoplasm there were numerous ribosomes (Fig. 7, arrows), most of which were associated in aggregates of loops and spirals (Fig. 8, r). Occasionally small elements of rough endoplasmic reticulum were also noted. The mitochondria appeared normal, and were round or elongate in form (Fig. 7, 


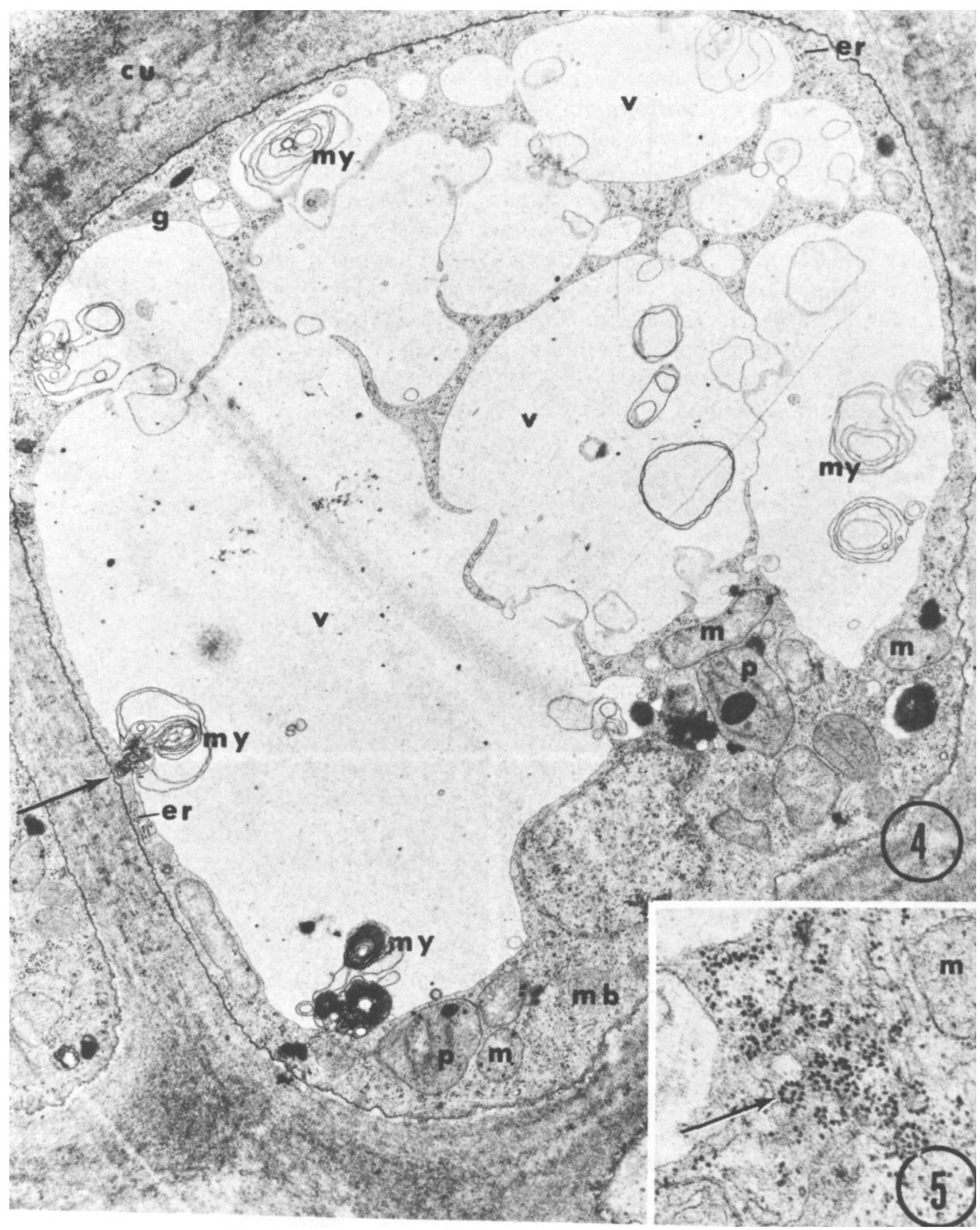

Figs. 4-5. Epidermal cells of maturing, dark green fruits. Note the numerous membrane configurations associated with the vacuole and tonoplast (Fig. 4, my), and the loops and spirals of ribosomes (Fig. 5, arrow).4) $\times 12,300 ; 5$ ) $\times 37,000$ respectively. 


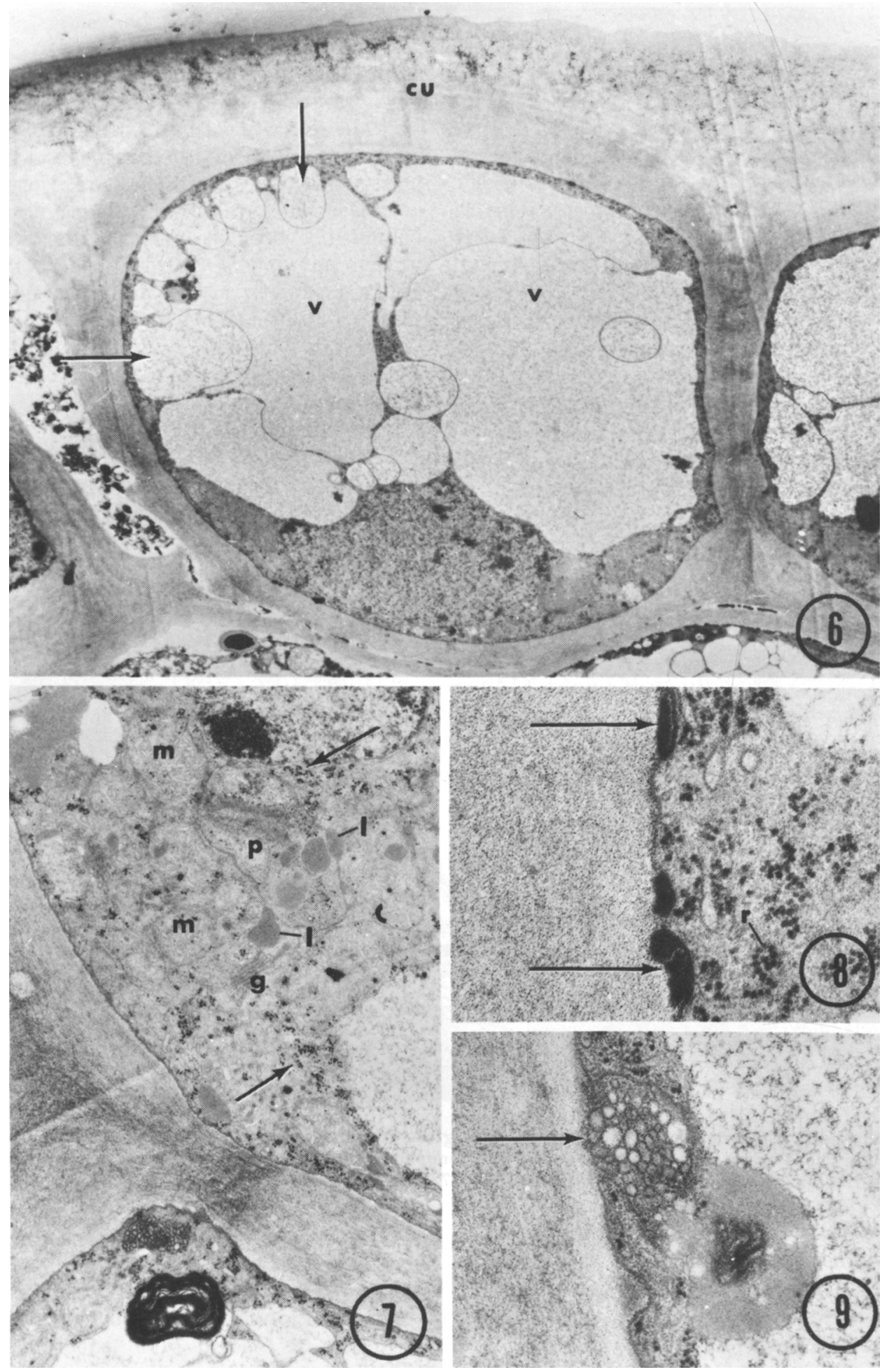

Figs. 6-9. Epidermal cells of maturing, light green fruits. 6) $\times 7,400$; 7) $\times 42,500$; $8) \times 21,500 ; 9) \times 40,000$. 
$\mathrm{m})$. There were only a few plastids per cell, but these were often elongate or amoeboid in form (Fig. 7, p). The grana of the plastids were small and not often observed, although occasionally two or three lamellae were present. Large plastoglobuli were also present in the plastids (Fig. 7, p). Golgi bodies were present in these cells, although few vesicles were associated with them (Fig. $7, g)$. Lipid bodies were present in the cytoplasm, often associated with organelles, particularly mitochondria and plastids (Fig. 7, 1). The microbodies appeared similar to those in the dark green fruits.

There were some unusual variations in the plasmalemma. Dark, lensshaped, lipid bodies frequently occurred between the membrane and the wall (Fig. 8, arrows), and invaginated pockets of the plasmalemma containing membranous vesicles occasionally were observed (Fig. 9, arrow). The outer cell wall and cuticle appeared as previously described in the late dark green fruits (Fig. 6, cu).

\section{Ripening (November-December)}

There were many variations in the ultrastructural features of the epidermal cells of the fruits undergoing the transition from green to orange, and variations in the vacuoles were particularly evident. Generally there were several vacuoles per cell, and the vacuolar contents varied from a light, fine, granular material (Fig. 12, v) to coarser, more dispersed granules (Fig. 13, v). Dense, irregular inclusions were not uncommon in the vacuoles (Fig. 14, v). Frequently the inner side of the tonoplast was extremely dense due to the accumulation of an unknown material along the inner surface (Fig. 13, v). Elliptical and lens-shaped lipid bodies also were often associated with the vacuolar membrane (Fig. 12, lv).

The nuclei of these cells were large, and spherical to ovate in form (Figs. 10,
$12,13, \mathrm{n})$. The chromatin was scattered, and generally was associated with the inner membrane of the nuclear envelope. The perinuclear space between the two nuclear membranes was frequently expanded (Fig. 13, ps), and there were many aggregates of ribosomes in the cytoplasm (Fig. 11, r). Small, scattered elements of rough endoplasmic reticulum were also present (Fig. 10, er), as were Golgi bodies (Fig. 11, g). The mitochondria varied from round to elongate, and appeared normal (Figs. 10, 12, $13, \mathrm{~m})$. Lipid bodies in the cytoplasm were associated with organelles (Fig. $13,1)$. The plastids were large, and each contained several dense plastoglobuli (Fig. 12, p), and occasionally, phytoferritin clusters.

The plasmalemma generally had an irregular or bumpy appearance, and the numerous multivesicular invaginations were often very large (Figs. 10, 11, arrows).

The outer cell wall and cuticle of the epidermal cells (Figs. 10, 13, cu) appeared similar to counterparts in the immature fruits, although occasionally small lacunae were present at the juncture of the wall between the two epidermal cells (Fig. 12, la).

\section{After-ripe (February and March)}

The fruits harvested at this time were large, deep orange, and appeared generally similar to normal ripe fruits. The epidermal cells contained several small to moderately large vacuoles (Figs. 15, $16, \mathrm{v})$ whose main content was a loosely distributed granular material. Occasionally some vacuoles had a heavier accumulation of granules. Myelin-like configurations of membranes within the vacuoles were frequently noted (Fig. $15, \mathrm{my}$ ), as was the association of lipid bodies with the vacuolar membrane.

The nuclei tended to be spherical, and the chromatin associated with the inner nuclear envelope was quite apparent (Fig. 15, n). Ribosomes were commonly 

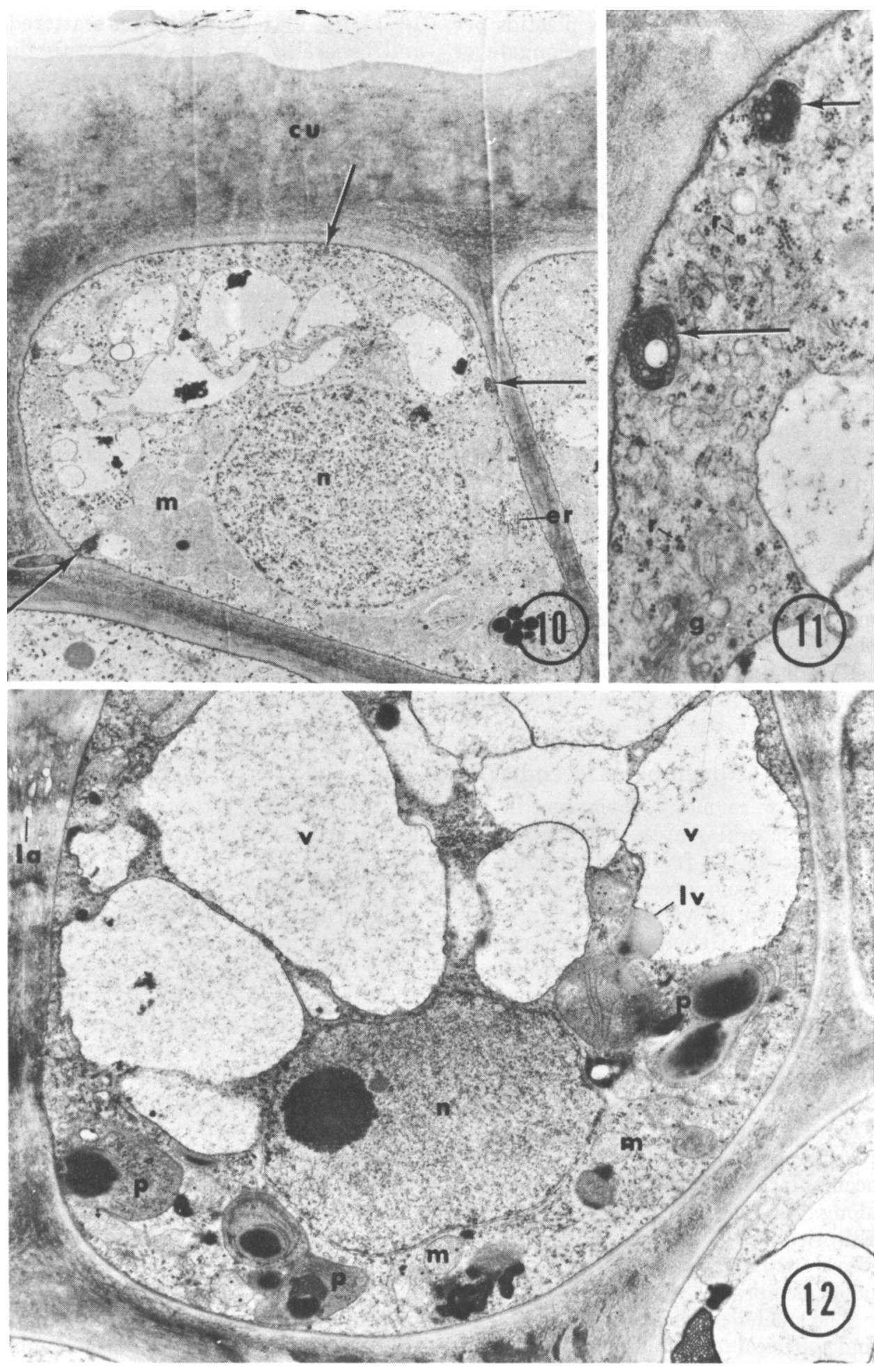

Figs. 10-12. Epidermal cells of fruits undergoing color change and ripening. 10) $\times 7,700$; 11) $\times 27,000$; 12) $\times 10,600$. 

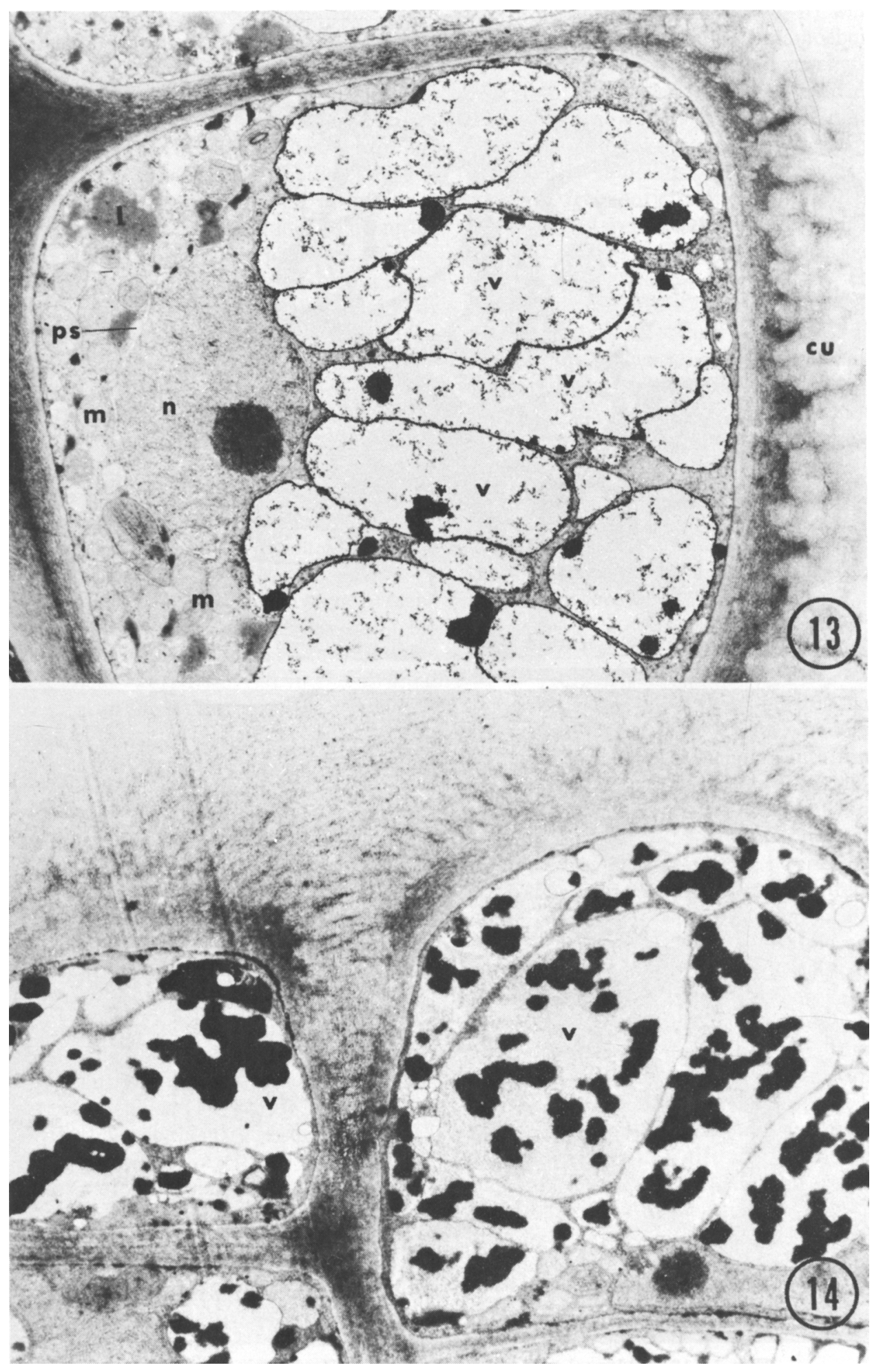

Figs. 13-14. Epidermal cells of fruits undergoing color change and ripening. 13) $\times 10,000$; 14) $\times 7,700$. 


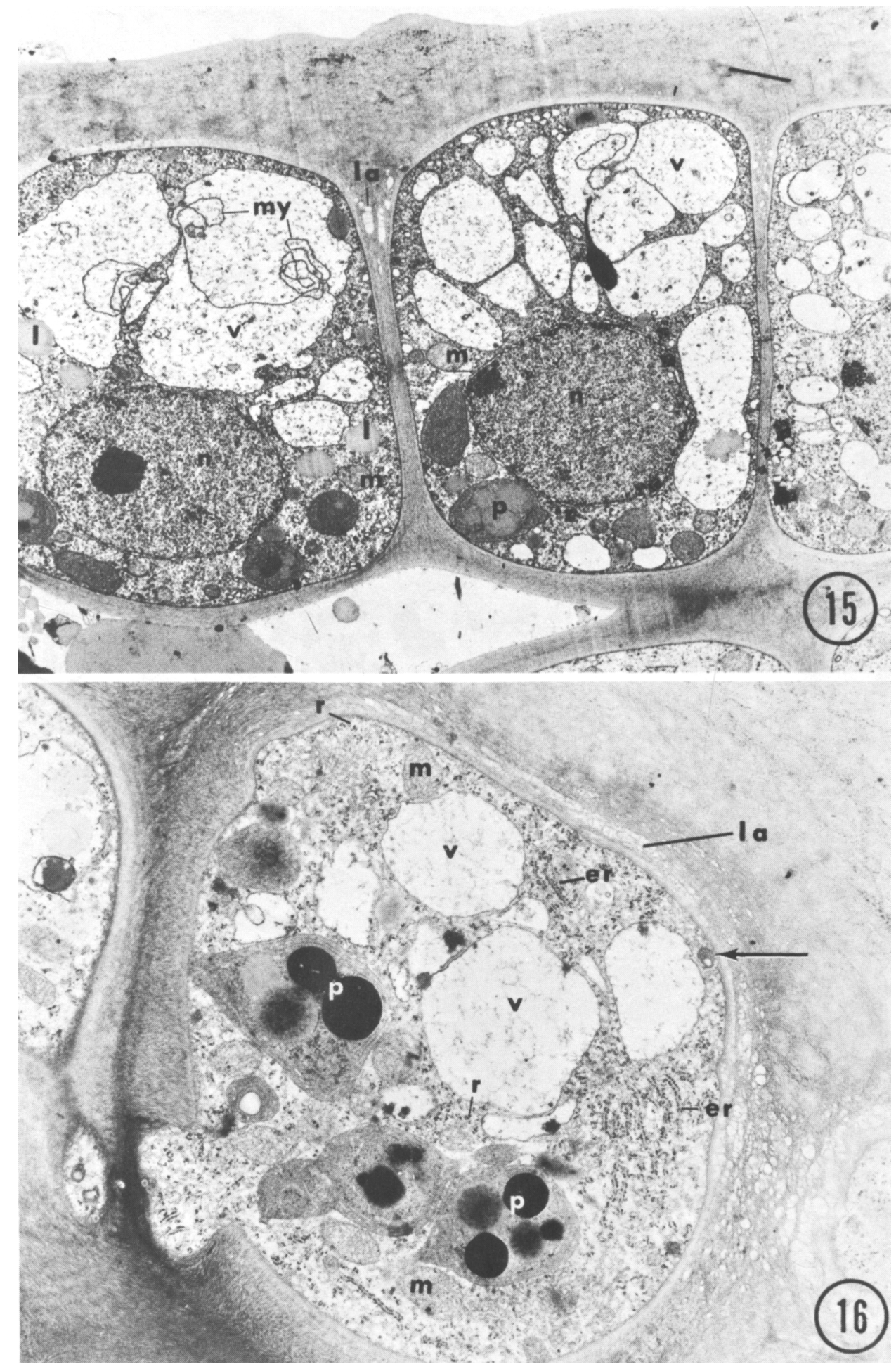

Figs. 15-16. Epidermal cells of fruits harvested after ripening had occurred. 15) $\times 6,400 ; 16) \times 12,000$. 
observed in the cytoplasm, most frequently in clusters (Fig. 16, r), although loops and spirals were not as apparent as in some earlier stages. Frequently there were moderate to large aggregates of rough endoplasmic reticulum (Fig. 16, er). Golgi bodies and microbodies were present, but no unusual characteristics were evident. The mitochondria were numerous (Figs. 15, 16, $\mathrm{m})$, and the plastids were very large and often irregular or amoeboid in shape. They contained several large plastoglobuli (Figs. 15, 16, p) and frequently clusters of phytoferritin, as well as a few peripheral lamellae. Lipid bodies also were present in the cytoplasm, (Fig. 15, 1), although most of these generally had an association with the tonoplast. Multivesicular pockets of the plasmalemma were common at this stage (Fig. 16, arrow).

Lacunae were almost always present at the outer juncture of the walls between cells (Fig. 15, la); and, in some instances, were observed in the striated region of the wall across the outer surface of the cell (Fig. 16, la).

\section{Early Senescence (April, May, early June)}

There was a great variation in the vacuoles in the epidermal cells of the early senescent fruits (Figs. 17, 18, v). There tended to be several medium-sized vacuoles, each with a uniform granular content. In some cells the vacuoles were densely packed with granules (Fig. 17, v). Some vacuoles had an irregular outline (Fig. 17, v), and lipid bodies were frequently associated with the tonoplast of the vacuoles (Fig. 17, 1).

In the cytoplasm, ribosomes (Fig. 18, r) occurred mainly in clusters; and elements of endoplasmic reticulum were observed only occasionally. The mitochondria were either round or elongate, and appeared normal (Figs. 17, 18, m). Golgi bodies were observed, but few vesicles were associated with Golgi cister- nae. The plastids (Figs. 17, 18, p) were large and often irregular or amoeboid in outline. Frequently, large aggregates of phytoferritin were present within them. Several very large plastoglobuli also were evident in each plastid; and peripheral lamellae, although often present, frequently appeared swollen. Lipid bodies were relatively common in the cytoplasm, and often were associated with organelles, particularly the surface of the plastids or myelin-like configurations of membranes (Fig. 17, 18 , arrows). The nuclei at this stage appeared comparable to those in earlier stages (Fig. 17, n). The plasmalemma seemed reasonably smooth, although occasional circlets and loops, as well as myelin-like configurations, were observed.

In the cell wall, the lacunae around the outer surface tended to be particularly numerous (Figs. 17, 18, la).

\section{Late Senescence (late June; July, August, and September)}

At this stage the epidermal cells usually contained several large vacuoles, although occasionally cells containing one large vacuole and several smaller, associated vacuoles were observed (Figs. $19,20,21,22, \mathrm{v})$. Also, vacuoles with irregular or jagged outlines were common (Figs. 20, 21, 22, v). The contents of the vacuoles were more variable than in earlier stages. In some cells, one vacuole would be filled with a loosely distributed granular material, whereas another vacuole, closely associated with, and apparently touching the first, would be filled with more compact and denser accumulations of granules (Fig. 19 , v). Some vacuoles, almost uniformly filled with granules, also contained lipid inclusions, some of which appeared to be protruding into the vacuoles from the cytoplasm (Figs. 20, 21, 22, 1). These inclusions were often stained with a very dense outer ring and an inner, more homogeneous, lightly staining re- 

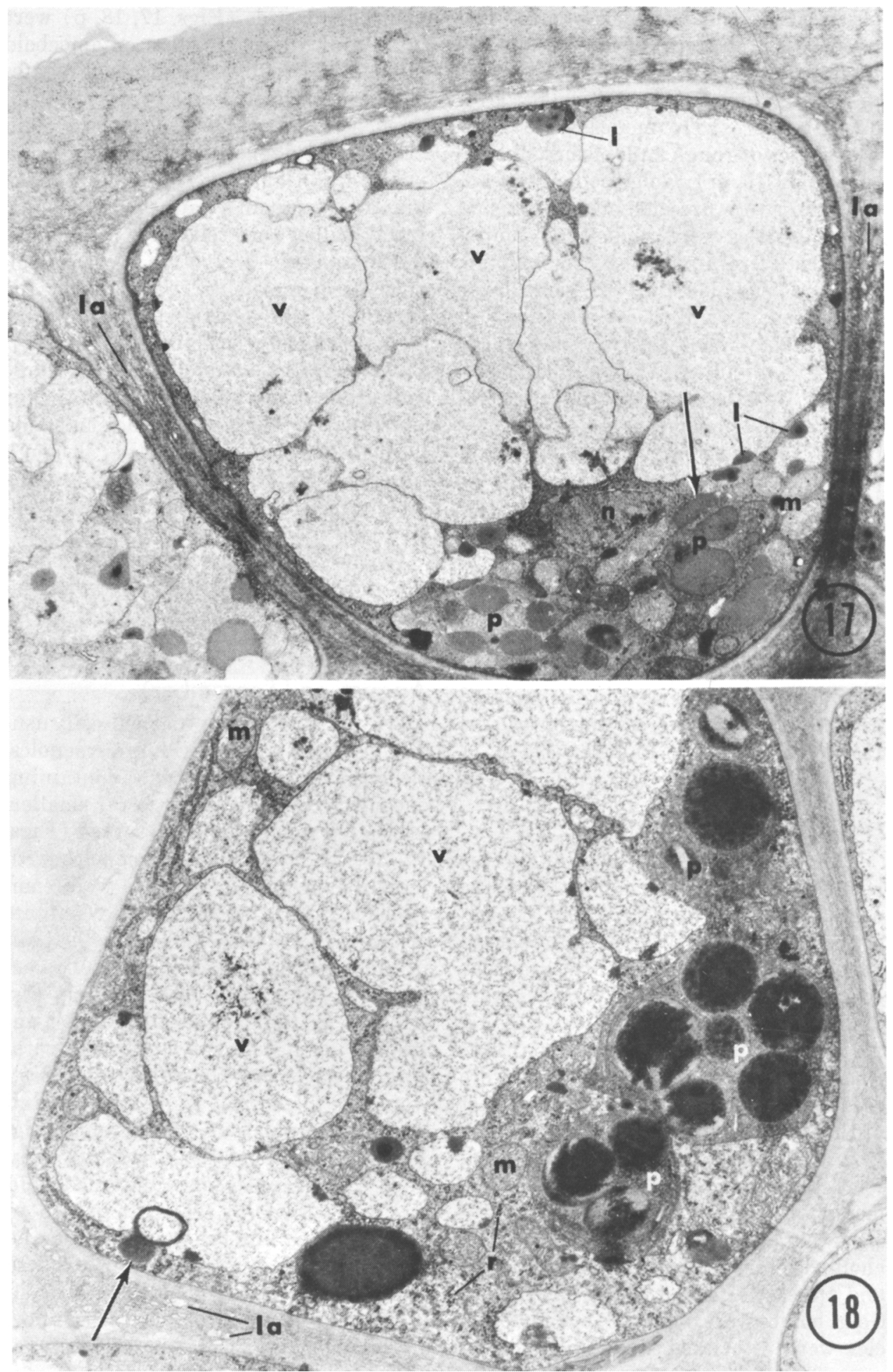

Figs. 17-18. Epidermal cells of early senescent fruits. 17) $\times 8,600$; 18) $\times 12,000$. 


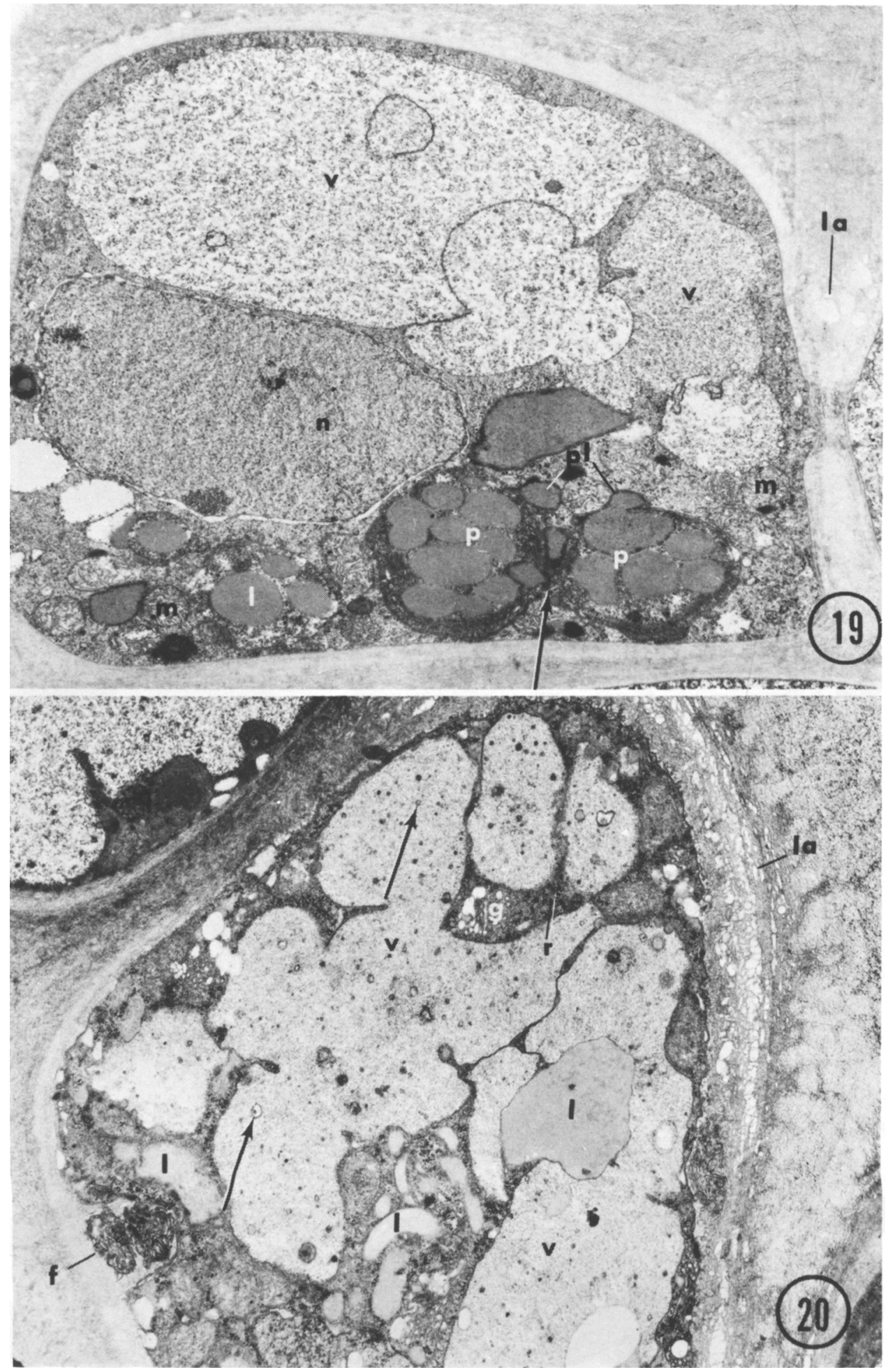

Figs. 19-20. Epidermal cells of late senescent fruits. 19) $\times 13,700 ; 20) \times 14,500$. 

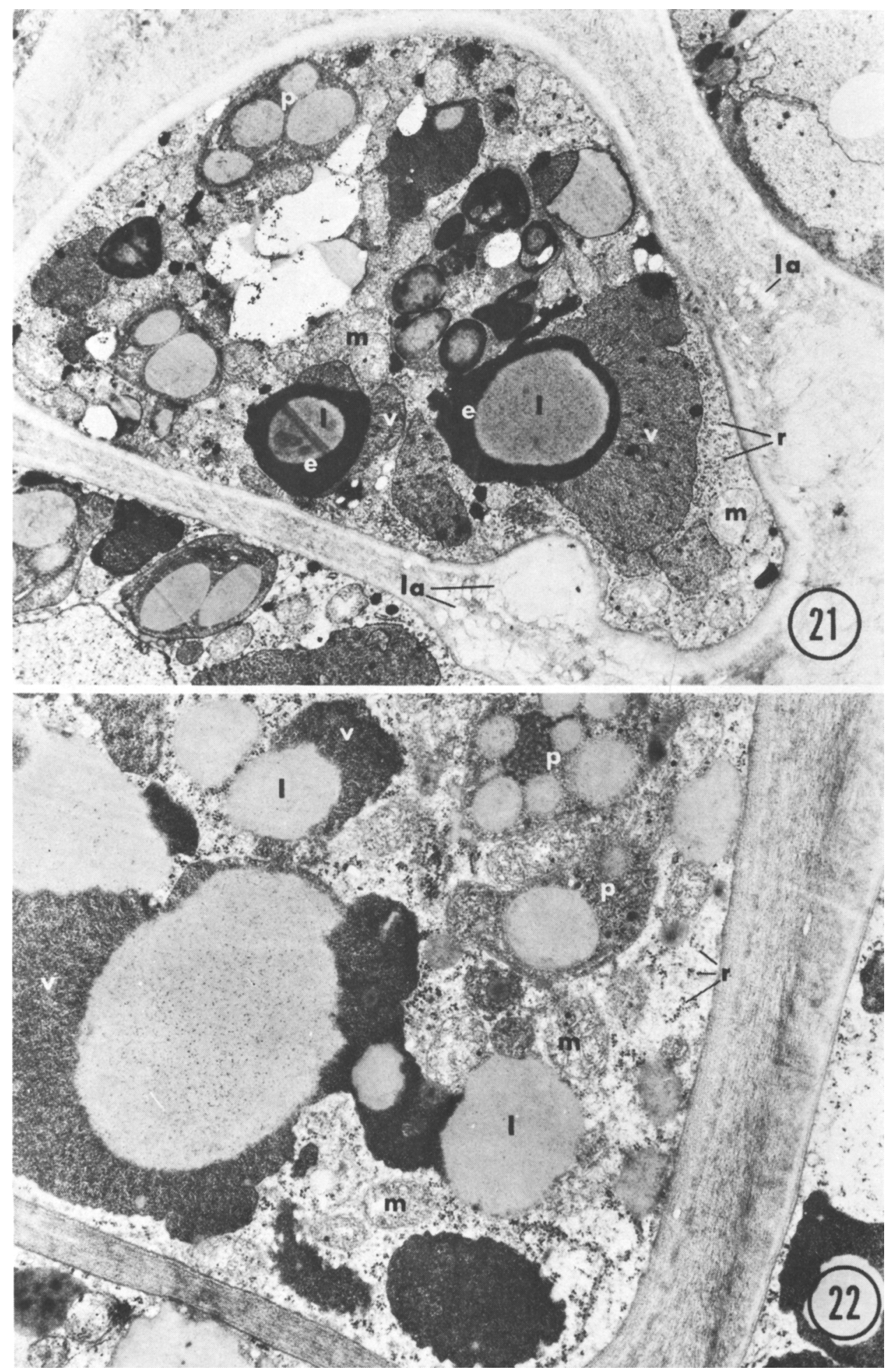

Figs. 21-22. Epidermal cells of late senescent fruits. 21) $\times 11,000 ; 22) \times 19,000$. 


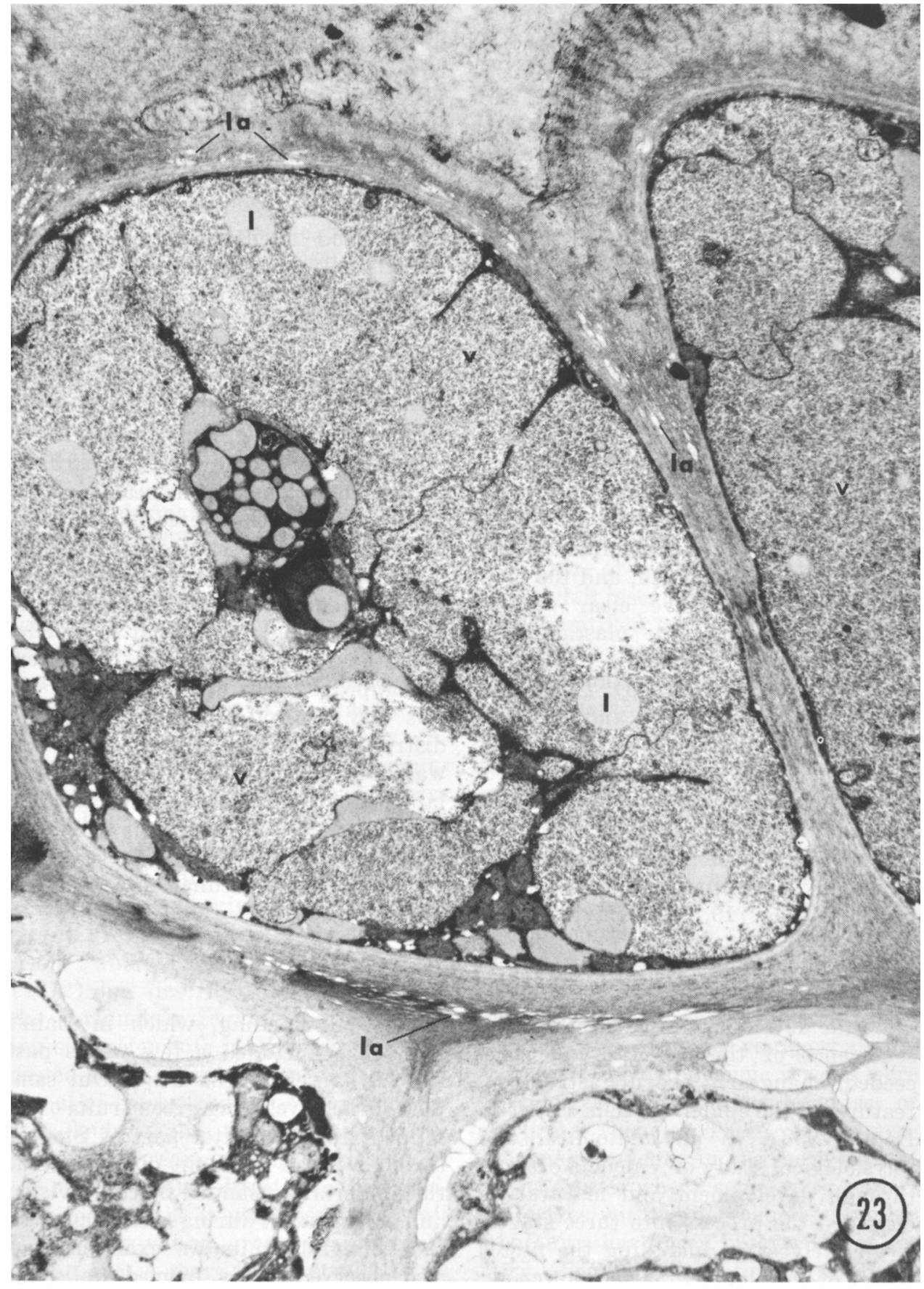

Fig. 23. Epidermal cell evidently in the terminal stage of senescence. $\times 10,000$. 
gion (Fig. 21, e). Small vesicles within the vacuoles also were a common occurrence (Fig. 20, arrows).

The nuclei were easily recognized and appeared much as in previous stages (Fig. 19, n). Although their number was less than in early stages, ribosomes also were present in the cytoplasm, generally in clusters (Figs. 20, 21, 22, r). However, there were few elements of rough endoplasmic reticulum. The groundplasm tended to be quite dense, and small vesicles scattered throughout were a frequent occurrence. Golgi bodies were observed in some cells, and small vesicles associated with this organelle were also evident (Fig. 20, g). There were several mitochondria per cell, either round or elongate (Figs. 19, 21, $22, \mathrm{~m})$. Often the mitochondrial membrane was poorly defined, and the matrix appeared to have clear regions (Figs. 21, 22, m). The plastids were large, but their number per cell was modest (Figs. 19, 21, 22, p). They often were irregular in outline, and, in many images, there were indications that fusion of plastids with each other was occurring (Fig. 19, arrow). The plastids contained a loose, granular stroma and several large plastoglobuli which often appeared to be protruding from the plastids (Fig. 19, pl). Phytoferritin clusters also were commonly observed in the plastids, and lipid bodies were frequently present in the cytoplasm (Fig. 19, 1). Many of these were associated with organelles, including both plastids and mitochondria. The plasmalemma frequently had an irregular contour, and massive collections of membranes and fibrils often occurred in pockets between the plasmalemma and the wall (Fig. 20, f).

Large numbers of lacunae were present in the walls on all sides of the cells (Figs. 19, 20, 21, la).

\section{Terminal Stage}

In a number of fruits taken from June to September, many, or nearly all, of the epidermal cells were considered to be in the terminal stage of senescence. This stage was characterized by a lack of discreteness of most membranes and organelles (Fig. 23). What organelles could be observed were often swollen, and appeared disrupted. The cytoplasm was very electron-dense, and was often distributed in a thin band along the wall. The vacuoles were densely granular (Fig. 23, v) and contained very little other material, except an occasional lipid body (Fig. 23, 1). There was a large number of lacunae in all the cell walls (Fig. 23, la).

\section{DISCUSSION}

As the development, maturation, and senescence of the Navel orange proceeded, changes in the ultrastructural features of the epidermal cells occurred. Bain (1958), in an anatomical and physiological study of Valencia oranges through development and maturation, classified the process into three stages: I. an early stage including the first 4 weeks of development after flowering; II. a second stage primarily dominated by the growth and enlargement of the fruits until they were yellow in color; and III. maturation, or what should be considered ripening, which in Bain's study also included a few weeks past normal harvest of the fruits. Our samples of the developing green fruits overlapped from the latter part of Stage I through Stage II. Bain observed that the epidermis expanded by cell division and enlargement during these stages. In the youngest fruits we examined, we also observed newly formed walls, indicative of cell division. However, during the major part of the period identified by Bain as Stage II, we did not find any evidence of cell division. As the 
fruits developed, a significant change occurred in the cuticle. At first the cuticle was relatively thin and homogeneous; but, with the enlargement of the fruit, it became thicker, and a marbled pattern of electron density appeared in the region between the outer cell wall and the homogeneous zone along the outer surface of the cuticle. These marbled images probably reflect compositional patterns. But no evidence indicating the presence of ectodesmata was found as described by Scott and Baker (1947) in light microscope studies, or by other investigators in electron $\mathrm{mi}$ croscopic studies of other organs (Franke, 1967, 1969; Litz and Kimmins, 1971).

The epidermal cells of the developing fruits contained the normal constituent of organelles such as mitochondria, endoplasmic reticulum, and ribosomes, an indication that they were reasonably active cells. However, no particular variations indicated a direct relationship with any one activity. The nuclei also resembled those of other tissues, although in many instances the perinuclear space of the nuclear envelope was expanded. A similar expansion of this space was observed in the nuclei of cells of the grapefruit rind undergoing degenerative changes induced by chilling, and in grapefruit at color break (PlattAloia and Thomson, 1975). Esau (1972) has described an expansion of the perinuclear region in differentiating sieve elements in Mimosa. She suggested that this expansion was the first signal of the breakdown of the nucleus. It is doubtful that the expansion of the perinuclear region in the epidermis of the rind is related directly to degenerative changes, as it was observed in all stages from young, green, ripe, to early senescence. A more likely possibility is that expansion of the perinuclear region is related to continued nuclear activity throughout the development and aging of the fruit.
The variations in the vacuoles, and the changes in the ultrastructural features of the vacuoles from one stage to the next, were of particular interest. The epidermal cells in almost all material had several vacuoles. In the youngest fruits examined, the major content of the vacuoles was a fine, granular material which varied from moderate to densely compact. The nature of this material is unknown. As the fruits enlarged and neared ripening, there was a dimunition of much of this granular material (compare Figs. 1, 4, and 6 with 11, 12, and 13), indicating that it may have been utilized in some fashion during this stage of development. During fruit ripening, dense, irregular bodies of material were often present within the vacuoles (Fig. 14). Again, the nature of the material is not known, although it resembles material which has been identified as tannins in other tissues (Ledbetter and Porter, 1970; Esau, 1973). In the after-ripe and early senescent fruits, these tannin-like bodies disappeared, and the granular contents of the vacuoles tended to increase. There was a further increase in granular contents during late senescence, and the vacuoles were often filled with an extremely condensed and granular material (see Fig. 22).

Concomitant with the changes in vacuolar content there were changes associated with the vacuolar membrane and cytoplasmic vesicles associated with the vacuoles. In the youngest fruits examined, the cytoplasmic vesicles were often associated with the tonoplast of the larger vacuoles. These vesicles were even more evident in the more mature green fruits, where some were apparently free within the vacuoles. Similar structures have been observed in a variety of other plant tissues, and the general consensus appears to be that the cytoplasmic vesicles and vacuolar pockets represent a pathway for movement of material into the vacuole 
(Thomson, 1967b; Walker and Bisulputra, 1967; Coulomb, 1968, 1973; Fineran, 1970, 1971; Mahlberg, Olson, and Walkinshaw, 1970; Villiers, 1971, 1972a, b; Mesquita, 1972; Matile, 1974). The most striking changes associated with the tonoplast were in the epidermal cells of the maturing green fruits prior to color change. The vacuoles were frequently subchambered, and many membranous inclusions were present within the vacuoles. Also, large, myelin-like, membranous configurations were associated with the tonoplast. These configurations extended into the vacuole from the tonoplast and associated cytoplasm, and often from the plasmalemma. There is considerable debate whether such membranous structures are artifacts induced during fixation (O'Brien, Kud, McCully, and Yee, 1973). If they are artifacts, then they would be expected to appear in all material fixed and prepared in the same manner. In this study they appeared dominantly only at one stage. Thus, we feel they are probably not artifacts, and that they are related to processes occurring at a particular stage in the maturation of the fruit.

During the past few years a growing body of evidence has accumulated indicating that the vacuole in plants has a lysosomal or lytic function (Poux, 1963, 1970; Matile, 1966, 1968, 1969a, b, 1974; Matile and Winkenbach, 1971; Coulomb, 1968, 1971a, b; Berjak, 1968, 1972; Fineran, 1970, 1971; Marty, 1971, 1972; Buvat, 1971). One of the apparent manifestations of this function is the engulfment of cytoplasm by membranes, and the subsequent migration of these vesicles into the central vacuole (Sievers, 1966; Villiers, 1967, 1971, 1972a, b; Coulomb, 1968; Marty, 1971; Mesquita, 1972). After migration into the vacuoles, the membranous vesicles and myelin-like configurations degenerate. It has been suggested that the breakdown products are subsequently re- leased to the cytoplasm and reutilized in the metabolism of the cell (Matile, 1968, 1974; Matile and Moor, 1968; Buvat, 1971; Fineran, 1971). The changes in granular content, the appearance of vacuolar pockets apparently migrating into large vacuoles, and the presence of membranous configurations and myelin-like figures which disappeared with ripening, correlate well with the above hypothesis of vacuolar function in the activity of the cell.

In the after-ripe and early senescent fruits, although vacuolar inpocketing and myelin-like membranous configurations were occasionally observed, the major shift in the vacuolar ultrastructure was an increase in granulation. This continued until the vacuoles were often irregular in outline and completely filled with densely packed granules. In the late-senescent fruits, large lipid bodies were also associated with, and accumulated within, the vacuoles. The migration of lipid material into vacuoles is probably a normal function in many plant tissues, and may be related to the lytic and recycling functions of vacuoles (Harris and Arnott, 1973). However, with the onset of senescence, the lytic and recycling capacities of the vacuoles appear to decrease, resulting in the heavy accumulation of granular and lipid material in the vacuole.

Typical cytoplasmic organelles were observed in all material examined up to the terminal stages. This may indicate that throughout the development, maturation, and early senescence of the epidermal cells many, if not all, the metabolic functions are more or less operative. This general interpretation fits well with results of biochemical and physiological studies of senescent systems. For example, the presence of ribosomal aggregates in all cells, including late-senescent material, coincides with the evidence that some protein synthesis occurs in most senescing sys- 
tems (Sacher, 1973). Further, the appearance of many elements of roughsurfaced endoplasmic reticulum during the early senescent stages (Fig. 15) is in concert with the evidence that new protein synthesis occurs with the onset of senescence (Sacher, 1973). Beginning in the early senescent stage and continuing through late senescence, the plastids become larger, more amoeboid in form, and develop more and larger plastoglobuli. These types of changes have been observed many times in senescing systems (Thomson, 1966, 1969; Dodge, 1970; Butler and Simon, 1971). It has also been found that beginning in early senescence and continuing through late senescence, there is an apparent decrease in number, evidently through the fusion of plastids.

In the late-senescent stage there is a loss of definition of membranes of the mitochondria, microbodies, and plastids, and a drastic reduction of other cytoplasmic membranes. These changes are likely to be degenerative, and probably result in dysfunctions relative to compartmentation and metabolism. The gradual degeneration of the membranes also supports the view, originally developed by Blackman and Parija (1928), that senescence is due to the loss of organizational resistance of the cells. In recent times the organizational integrity of cells has been taken to be the preservation of membrane structure and function (Bain and Mercer, 1964; Butler and Simon, 1971; Sacher, 1973; Simon, 1974).
Many of the changes in the plasmalemma of the epidermal cells were subtle and probably related to shifting functions. Multivesicular enclaves became more apparent during after-ripening and early senescence. Similar structures have been described previously, although their significance is far from clear (Thomson, 1967a; Marchant and Robards, 1968; Mahlberg, Olson, and Walkinshaw, 1970, 1971). Appearance of the multivesicular invaginations in the epidermal cells tends to correlate with the formation of lacunae and loosening of the cell walls; however, whether there is a direct relationship is still questionable. The large bodies of dense fibrils which appeared in the wall adjacent to the plasmalemma during the senescent periods are also probably related to wall degradation processes.

The evidence from these studies indicates that with senescence there is a gradual loss of lytic, and possibly recycling, functions of the vacuoles. This is indicated by the large accumulation of granules and lipid material, a slow deterioration of cellular membranes of organelles, and a final loss of membranes, including the plasmalemma. The simplest interpretation is that the epidermal cells gradually lose the capacity to maintain cellular metabolism and membrane integrity.

Acknowledgment. This study was supported in part by a grant, BMS-7419987, from the National Science Foundation. 


\section{LITERATURE CITED}

BAIN, J. M.

1958. Morphological, anatomical and physiological changes in developing fruit of Valencia orange, Citrus sinensis (L). Osbeck, Austral. Jour. Bot. 6:1-24.

BAIN, J. M., and F. V. MERCER

1964. Organization resistance and the respiration climacteric. Austral. Jour. Biol. Science 17: 78-85.

BerJaK, $\mathrm{P}$.

1968. A lysosome-like organelle in the root cap of Zea mays. Jour. Ultrastruct. Res. 23: 233-242.

1972. Lysosomal compartmentation: Ultrastructural aspects of the origin, development and function of vacuoles in Lepidium sativum. Ann. Bot. 36:73-81.

Biale, J. B.

1964. Growth, maturation and senescence in fruits. Science 146:880-888.

Blackman, F. F., and P. PariJa

1928. Analytic studies in plant respiration. I. The respiration of a population of senescent ripening apples. Proc. Roy. Soc. B. 128:412-445.

Butler, R. D., and E. W. Simon

1971. Ultrastructural aspects of senescence in plants. Adv. Gerontol. Res. 3:73-129.

Buvat, $R$.

1971. Origin and continuity of cell vacuoles. In: Origin and Continuity of Cell Organelles. (eds. J. Reinert and H. Ursprung). Springer-Verlag, New York, Heidelberg and Berlin. 127-157.

Coulomb, C.

1973. Diversité des corps multivésiculaires et notion d'hétérophagie dans le méristème radiculaire de scorsonère (Scorzonera hispanica). Jour. Microscop. 16:345-360.

Coulomb, $\mathrm{P}$.

1968. Sur la présence de structures lamellisées dans les cellules méristématiques de bourgeon de Solanum tuberosum. C. R. Acad. Sci. 267:1373-1374.

1971a. Phytolysosomes dans de méristème radiculaire de la courge (Cucurbita pepo L.) Cucurbitacée. Activité phosphatasique acide et activité peroxydasique. C. R. Acad. Sci. 272:48-51.

1971b. Sur la présence de phytolysosomes dans les cellules de tumeurs de la plantule de Pois (Pisum sativum L.) induites par l'Agrobacterium tumefaciens. C. R. Acad. Sci. 272:1229-1231.

DODGE, J. D.

1970. Changes in chloroplast fine structure during autumnal senescence of Betula leaves. Ann. Bot. 34:817-824.

EsAU, K.

1972. Changes in the nucleus and the endoplasmic reticulum during differentiation of a sieve element in Mimosa pudica L. Ann. Bot. 36:703-710.

1973. Comparative structure of companion cells and phloem parenchyma cells in Mimosa pudica L. Ann. Bot. 37:625-632.

Fineran, B. A.

1970. An evaluation of the form of vacuoles in thin sections and freeze-etch replicas of root tips. Protoplasma 70:457-478.

1971. Ultrastructure of vacuolar inclusions in root tips. Protoplasma 72:1-18.

Franke, W.

1967. Mechanisms of foliar penetration of solutions. Ann. Rev. Plant Physiol. 18:281-300.

1969. Ectodesmata in relation to binding sites for inorganic ions and urea on isolated cuticular membrane surfaces. Amer. Jour. Bot. 56:432-435.

HARRIS, J. B., and H. J. ARNOTT

1973. Effects of senescence on chloroplasts of the tobacco leaf. Tissue and Cell. 5(4): 527-544.

KARNOVSKY, M. J.

1965. A formaldehyde-glutaraldehyde fixative of high osmolarity for use in electron microscopy. Jour. Cell Biol. 27:137A. 
Ledbetter, M. C., and K. R. Porter

1970. Introduction to the fine structure of plant cells. Springer-Verlag, Berlin, Heidelberg, New York.

Litz, R. E., and W. C. Kimmins

1971. Interpretation of ectodesmata in relation to susceptibility to plant viruses. Can. Jour. Bot. 49:2011-2014.

Mahlberg, P., K. Olson, and C. Walkinshaw

1970. Development of peripheral vacuoles in plant cells. Amer. Jour. Bot. 57:952-960.

1971. Origin and development of plasma membrane derived invaginations in $\nabla$ inca rosea L. Amer. Jour. Bot. 58:507-416.

Marchant, R., and A. W. Robards

1968. Membrane systems associated with the plasmalemma of plant cells. Ann. Bot. 32: 457-471.

MARTY, M. F.

1971. Vésicules autophagiques des laticifères différenciés d'Euphorbia characias L. C. R. Acad. Sci. 272:399-402.

1972. Distribution des activitiés phosphatasiques acides au cour du processes d'autophagie cellulaire dans les cellules du méristème radiculaire d'Euphorbia characias L. C. R. Acad. Sci. 274:206-209.

MATile, $\mathrm{PH}$.

1966. Enzyme der Vakuolen aus Wurzelzellen von Maiskeimlingen. Ein Beitrag zur funktionellen Bedeutung der Vakuole bei der intrazellularen Verdauung. Z. Naturf. 21b: 871-878.

1968. Lysosomes of root tip cells in corn seedlings. Planta 79:181-196.

$1969 a$. Vacuoles as lysosomes of plant cells. Biochem. J. 111:26-27.

1969b. Plant lysosomes. In: Lysosomes in Biology and Pathology (ed. J. T. Dingle and H. B. Fell) North Holland Publ. Co., Amsterdam and London. 406-430.

1974. Lysosomes. In: Dynamics of Plant Ultrastructure (ed. A. W. Robards). McGrawHill Book Co. (U.K.) Limited, England, 178-218.

Matile, Ph., and H. MoOR

1968. Vacuolation: origin and development of the lysosomal apparatus in root-tip cells. Planta 80:159-175.

Matile, Ph., and F. Winkenbach

1971. Function of lysosomes and lysosomal enzymes in the senescing corolla of the morning glory (Ipomoea purpurea). Jour. Exp. Bot. 22:759-771.

Mesquita, J. F.

1972. Ultrastructure de formations comparable aux vacuoles autophagiques dans les cellules des racines de l'Allium cepa L. et du Lupinus albus L. Cytologia 37:95-110.

O'Brien, T. P., J. Kud, M. E. McCully and S-Y YeE

1973. Coagulant and non-coagulant fixation of plant cells. Austral. Jour. Biol. Sci. 23:12311250.

Plate-Aloia, K. A., and W. W. Thomson

1976. An ultrastructural study of two forms of chilling-induced injury to the rind of grapefruit (Citrus paradisi, Macfed). Cryobiology 13:95-106.

Poux, N.

1963. Localisation de la phosphatase acide dans les cellules méristématiques de Blé (Triticum vulgare Vill.). Jour. Microscopie 2:485-489.

1970. Localization d'activités enzymatiques dans le méristème radiculaire de Cucumis sativus L. III. Activité phosphatique acid. Jour. Microscopie 9:407-434.

REYNOLDS, E. S.

1963. The use of lead citrate at high pH. as an electron opaque stain in electron microscopy. Jour. Cell Biol. 17:208-212.

SACHer, J. A.

1973. Senescence and postharvest physiology. Ann. Rev. Plant Physiol. 24:197-224.

SCOTT, F. M., and K. C. BAKER

1947. Anatomy of Washington navel orange rind in relation to water spot. Bot. Gaz. 108: 459-476. 
Sievers, A.

1966. Lysosomen-ahnliche Kompartimente in Pflanzenzellen. Naturwissenschaften 53: 334-35.

Simon, E. W.

1974. Phospholipids and plant membrane permeability. New Phytol. 73:377-420.

SPURR, A. R.

1969. A low-viscosity epoxy resin embedding medium for electron microscopy. Jour. Ultrastruct. Res. 26:31-43.

Thomson, W. W.

1966. Ultrastructural development of chromoplasts in Valencia oranges. Bot. Gaz. $127(2-3)$ : 133-139.

1967a. Electron microscope studies on some modifications of the plasmalemma in oranges. Jour. Ultrastruct. Res. 17:475-486.

1967b. Electron microscopic evidence for membrane bound structures in plant vacuoles. Proc. 25th Electron Micro. Soc. Am. 76-77.

1969. Ultrastructural studies on the epicarp of ripening oranges. Proc. First Int. Citrus Symp. 3:1163-1169.

Thomson, W. W., L. N. Lewis, and C. W. CogGrns

1967. The reversion of chromoplasts to chloroplasts in Valencia oranges. Cytologia 32: 117-124.

VILLIERS, T. A.

1967. Cytolysosomes in long-dormant plant embryo cells. Nature, 214:1356-1357.

1971. Lysosomal activities of the vacuole in damaged and recovering plant cells. Nature. 233:57-58.

1972a. Cytological studies on dormancy. II. Pathological aging changes during prolonged dormancy and recovery upon dormancy release. New Phytol. 71:145-152.

1972b. Cytological studies in dormancy. III. Changes during low temperature dormancy release. New Phytol. 71:153-160.

WALKER, W., and T. BisulPUTRA

1967. Fine structure of vesicle association with the cell surface in Helianthus shoot tissue. Can. Jour. Bot. 45:2103-2108. 
The journal HILGARDIA is published at irregular intervals, in volumes of about 650 to 700 pages. The number of issues per volume varies.

Single copies of any issue may be obtained free, as long as the supply lasts; please request by volume and issue number from:

\author{
PUBLICATIONS \\ UNIVERSITY OF CALIFORNIA \\ DIVISION OF AGRICULTURAL SCIENCES \\ 1422 South 10th Street \\ Richmond, California 94804.
}


